\title{
NEW SPIRITUAL MOVEMENT: Menelisik Visi Transformatif Komunitas Lia Eden sebagai Embrio Lahirnya New Age di Indonesia
}

\author{
Mohammad Takdir \\ Institut Ilmu Keislaman Annuqayah (INSTIKA) Sumenep \\ e-mail: mohammad.takdir@yahoo.com
}

\begin{abstract}
This research aims to explain the phenomenon of Lia Eden community which is a new spiritual movement in the dynamics of religious life in Indonesia. Some points to be described in this research are related with a background of the birth and development of the Lia Eden community, teaching, and transformative vision in the public sphere. This research is a case study of the Lia Eden community that became of the New Age movement in the wake of belief in formal religions that considered failure in overcoming the modern human crisis. This research shows that Lia Eden community is a new spiritual movement who tried to awaken a spirit of all religions so that able to overcome of a social problem in society. This movement is not ambitions to establish a new religious institution with a strict and doctrinal organization, but effort to transmit spiritual power at the individual level to become a reflection of the mystical movement that brought changes to human life.
\end{abstract}

\begin{abstract}
Abstrak: Penelitian ini bertujuan untuk menjelaskan fenomena komunitas Lia Eden yang merupakan gerakan spiritualitas baru dalam dinamika kehidupan beragama di Indonesia. Beberapa poin yang ingin dijabarkan dalam penelitian ini adalah berkaitan dengan latar belakang kelahiran dan perkembangan komunitas Lia Eden, ajaran, dan visi transformatifnya dalam ruang publik. Penelitian ini merupakan studi kasus dari komunitas Lia Eden yang menjadi bagian dari Gerakan Zaman Baru (New Age Movement) di tengah memudarnya kepercayaan terhadap agama formal yang dianggap gagal dalam mengatasi krisis kemanusian modern. Penelitian ini menunjukkan bahwa komunitas Lia Eden merupakan gerakan spiritualitas baru yang berupaya membangkitkan roh dari semua agama agar berperan dalam mengatasi masalah sosial di masyarakat. Gerakan ini tidak berambisi untuk mendirikan institusi baru yang bersifat keagamaan dengan organisasi yang ketat dan bersifat doktrinal, melainkan berupaya untuk mentransmisikan kekuatan spiritual pada level individu hingga menjadi cerminan dari gerakan mistik yang membawa perubahan bagi kehidupan manusia.
\end{abstract}

Keywords: gerakan keagamaan; spiritualitas; religious movement; new age; Lia Eden 


\section{A. Pendahuluan}

Salah satu tema penting dalam membaca fenomena kehidupan agama di Indonesia adalah munculnya gerakan agama baru yang sering diidentifikasi sebagai aliran sempalan (splinter group), dengan arus utama agama-agama tradisional yang telah mapan di tengah-tengah kehidupan masyarakat. Situasi semacam ini sering diilustrasikan sebagai bagian dari narasi mengenai hubungan antara ekspresi agama dan tatanan masyarakat yang mengalami kekacauan (chaos), karena adanya benturan yang sangat tajam antar kelompok keagamaan.

Fenomena maraknya gerakan aliran keagamaan di Indonesia patut mendapatkan perhatian dari pemerintah. Gerakan keagamaan ini muncul sebagai reaksi atas protes yang menyebabkan pemberontakan terhadap institusi agama formal yang dianggap tidak mampu menyelesaikan berbagai krisis kemanusiaan modern. Gerakan keagamaan tersebut mengklaim bahwa institusi-institusi agama belum memberikan jawaban baru atas pertanyaan manusia yang ikut serta dalam kemajuan ilmu pengetahuan dan teknologi (modernitas). Situasi inilah yang menjadi salah satu pendorong untuk mendirikan komunitas spiritual dengan berakar pada agama formal yang sudah mapan.

Reaksi berupa protes yang berujung pada pemberontakan ini bisa dilakukan dengan mendirikan agama baru untuk melawan eksistensi agama formal, membuat sinkretis atas ajaran agama-agama, atau mencari jawaban dengan mendirikan aliran spiritualitas baru yang bisa memberikan pencerahan bagi terciptanya tatanan kehidupan yang lebih menjanjikan. Fenomena ini jelas mengancam eksistensi institusi agama formal yang lebih dulu berkembang dalam mewarnai dinamika keberagamaan masyarakat Indonesia.

Kemunculan aliran baru atau gerakan keagamaan yang dinilai menyimpang oleh agama mainstream, sesungguhnya tidak lepas dari adanya kesadaran akan krisis kejiwaan manusia modern. Mereka mencari makna hidup, sambil merenungkan akar tradisi kerohanian dalam agama mereka sendiri yang menopang penemuan makna itu. Fisikawan genius, Fritjof Capra, ${ }^{1}$ menyebutnya

1Fritjof Capra, The Turning Point, Science, Society, and the Rising Culture (New York: Bantam Book, 1987), 125. 
sebagai "state of profound, and world wide crisis." Pernyataan Capra tentu berdasarkan fenomena yang terjadi dalam kehidupan umat manusia, di mana antara satu dengan yang lain saling mencengkram dan melakukan tindakan kekerasan secara membabi-buta.

Krisis kejiwaan yang terjadi dalam era milineal sekarang ini, tentu menjadi pemantik bagi para spiritualis untuk mengusung gerakan agama baru yang relevan dengan perkembangan zaman. Para spiritualis yang tergabung dalam new religious movement cenderung mengkritik institusi agama yang dianggap gagal dalam mengatasi berbagai persoalan kehidupan. Pemikir New Age, Wouter J. Haneraaff (1996), ${ }^{2}$ menyebut krisis kemanusiaan modern sebagai " $a$ point of extreme danger to humanity and the planet as a whole". Fenomena ini tidaklah berangkat dari ruang kosong, melainkan berdasarkan pada kenyataan bahwa manusia modern telah kehilangan kesadaran eksistensial untuk beragama secara sehat dan penuh dengan kearifan. Yang terjadi justru, banyak dari kaum beragama di Indonesia yang dari sisi perilakunya, telah melenceng dari ajaran agama dan terkadang antara kaum beragama saling menghujat dan mencaci satu sama lain.

Kemunculan aliran agama baru sesungguhnya berakar dari krisis spiritual dan moral yang dialami oleh kaum beragama, terutama yang meyakini institusi agama formal. Kemunculan gerakan keagamaan baru (new religious movement), membuat kita bertanya-tanya, apakah institusi agama sudah tidak relevan lagi bagi kehidupan individu? Jawaban awal yang diberikan mungkin saja adalah bahwa hal ini terkait erat dengan perubahan sosial dalam masyarakat dan agama, seperti radikalisme, fundamentalisme, sekularisasi, dan perubahan sosial (sosial change) lainnya. Akibat perubahan dan pergerakan sosial (social movement) yang begitu cepat, cara pandang masyarakat terhadap agama pun turut berubah, bahkan cenderung tidak peduli lagi dengan nasehat-nasehat yang diajarkan dalam agama formal.

Dalam menguraikan fenomena kemunculan agama baru di Indonesia, peneliti tertarik dengan gerakan Lia Eden sebagai salah satu gerakan spiritual baru yang mengusung keinsyafan rohani dalam mengatasi krisis kemanusiaan modern. Sebagai salah satu gerakan baru yang muncul di Indonesia, aliran ini

2 Wouter J. Hanegraaff, New Age Religion \& Western Culture, Esotericism in the Mirror of Seculer Thought (New York: Bantam Book, 1996), 344. 
berhasil memperoleh cukup banyak pengikut walaupun pada akhirnya juga tidak begitu berkembang. Penelitian terdahulu yang sangat konsen pada komunitas Lia Eden atau ajaran Salamullah sebagai bagian dari new religious movement adalah penelitian Al Makin yang berjudul "Challenging Islamic Ortodhoxy: Accounts of Lia Eden and Other Prophets in Indonesia". Al Makin melakukan penelitian tentang gerakan Lia Eden yang menjadi pusat perhatian masyarakat, karena pemimpinnya mengaku sebagai Nabi yang menerima wahyu dari Tuhan. Bagi Al Makin, gerakan Lia Eden adalah fenomena keagamaan yang muncul dalam konteks Indonesia sebagai sebuah aliran kebatinan yang mengusung keinsyafan rohani dengan merepresentasikan dirinya sebagai Ratu Adil yang bertugas menyelamatkan umat manusia dari krisis spiritual. $^{3}$

Sebagai salah satu gerakan keagamaan kontemporer yang berkembang, komunitas Lia Eden patut mendapatkan perhatian serius dari kalangan terkait yang konsen pada gejala New Age yang menampilkan varian baru dalam konteks keberagamaan. Lia Eden adalah bagian dari embrio New Age yang menampilkan spiritualitas sebagai instrumen fundamental dalam mengobarkan semangat anti agama (menolak agama formal) yang dianggap gagal dalam mengatasi krisis kemanusiaan modern.

Ketertarikan peneliti terhadap gerakan Lia Eden tentu bukan karena aliran ini tidak begitu berkembang dalam membolisasi massa dan pengikut yang banyak, melainkan gerakan ini menghadirkan sebuah warna baru dalam dinamika kehidupan keagamaan di Indonesia yang cenderung mengobarkan nilai-nilai spiritualitas dan moralitas. Sebagai aliran yang kontroversial, kemunculan komunitas Lia Eden patut mendapatkan perhatian serius bagi institusi agama formal yang merasa dilecehkan dengan kehadiran gerakan ini yang cenderung menyamakan semua agama tanpa terkecuali.

\section{B. Profil dan Napak Tilas Komunitas Lia Eden}

Dalam mengurai visi transformatif komunitas keagamaan, penting kiranya menjelaskan seputar profil tokoh sentral yang menjadi pelopor dari setiap gerakan yang dilakukan. Lia Aminuddin adalah tokoh utama dari komunitas Lia

${ }^{3} \mathrm{Al}$ Makin, Challenging Islamic Ortodhoxy: Accounts of Lia Eden and Other Prophets in Indonesia (Switzerland: Springer International Publishing, 2016), 18. 
Eden yang berasal dari Surabaya, Jawa Timur. Lia Eden adalah sapaan akrabnya yang menjadi pemimpin dalam komunitas spiritual yang memiliki daya tarik di tengah-tengah kehidupan masyarakat. Lia Aminuddin lahir dari pasangan Abdul Ghaffar dan Zainab, yang berprofesi sebagai pedagang sekaligus sebagai penceramah di kalangan warga Muhammadiyah. Lia Aminuddin hanya lulusan SMA dan berprofesi sebagai perangkai bunga dan pemandu acara yang berkaitan dengan cara merangkai bunga yang tayang di TVRI. ${ }^{4}$

Lalu bagaimana dengan latar belakang kelahiran komunitas Lia Eden? Kelahiran sebuah gerakan keagamaan sesungguhnya tidak bisa lepas dari beberapa peristiwa unik yang menawarkan pencerahan spiritual dengan alam gaib. Peristiwa unik dan ajaib adalah sesuatu yang lazim terjadi ketika seseorang mengklaim menerima wahyu atau ilham. Dari klaim inilah, seseorang yang merasa dirinya menerima wahyu atau ilham, akan senantiasa meyakinkan orang lain untuk percaya terhadap pencerahan yang diterimanya. Biasanya orang tersebut akan mengatakan bahwa ia ditakdirkan Tuhan sebagai pembawa risalah atau penyambung lidah dari firman Tuhan. Tidak heran bila dalam kehidupan modern sekarang ini, banyak orang yang mengklaim dirinya sebagai nabi karena merasa memperoleh ilham dari Tuhan. Bahkan, sekarang ini, banyak orang yang bercita-cita menjadi nabi, padahal kenabian adalah berasal dari Tuhan. Dengan kata lain, yang muncul sekarang ini adalah nabi-nabi palsu yang bermimpi akan dianggap sebagai pembebas umat, dipuji, dan menjadi pencerah bagi kehidupan umat manusia. ${ }^{5}$

Kelahiran sebuah gerakan keagamaan berakar dari kesadaran keilahian yang terpancar luas dalam bingkai kedamaian hati dan nilai-nilai spiritual yang tinggi. Bagi orang yang mengalami petualangan spiritual, kesadaran keilahian semakin memuncak dan memunculkan semangat baru dalam mendefinisikan tentang peran agama dewasa ini. Ketika memasuki dunia spiritual, seseorang bisa saja melakukan pemberontakan dengan mengecam keras institusi agama formal yang dianggap gagal dalam melahirkan ketenangan batin dan keinsyafan rohani bagi pemeluknya.

${ }^{4}$ A. Yogaswara and Maulana Ahmad Jalidu, Aliran Sesat dan Nabi-nabi Palsu: Riwayat Aliran Sesat dan Para Nabi Palsu di Indonesia (Yogyakarta: Narasi, 2008), 24. 19.

${ }^{5}$ Al Makin, Nabi Palsu: Membuka Kembali Pintu Kenabian (Yogyakarta: Ar-Ruzz Media, 2003), 
Dalam perkembangan kehidupan agama dewasa ini, ketenangan batin kini seolah menjadi barang yang mahal. Kekerasan dan konflik yang melibatkan komunitas agama dipandang sebagai kegagalan institusi agama dalam mengayomi pemeluknya untuk meredam segala perselisihan dan ketidakharmonisan yang melahirkan cita-cita perdamaian menjadi utopia belaka. Upaya menemukan jati diri dapat mendorong seseorang untuk menelusuri komunitaskomunitas spiritual lintas agama. Kegundahan, kecemasan, dan kegamangan merupakan persoalan yang muncul ketika seseorang sedang melakukan pengembaraan spiritual demi mendapatkan ketenangan batin yang lebih mencerahkan.

Begitu juga dengan seseorang yang mengalami peristiwa ajaib terkait dengan pengalaman spiritual yang menunjukkan pancerahan jiwa yang mengkilap. Peristiwa ini ternyata dialami langsung oleh Lia Aminuddin sebagai pemimpin spiritual yang mengaku mendapatkan pengalaman hidup yang cukup mendebarkan. Ada satu kejadian yang dianggapnya disebut sebagai sebuah keajaiban, di mana ia pernah menyaksikan langsung sebuah bola yang berwarna kuning mengelilingi angkasa dan hilang begitu saja di atas kepalanya. Kejadian itu terjadi ketika Lia duduk bersama kakak mertuanya pada tahun 1974 di serambi rumahnya. Peristiwa ini mengindikasikan sebuah sinyalamen akan datangnya pesan-pesan keilahian yang diklaim sebagai manifestasi Tuhan oleh Lia sendiri.

Sementara peristiwa ajaib kedua yang telah mengubah prinsip hidupnya terjadi pada malam 27 Oktober1995 kala dia sedang bersantai. Kejadian yang kedua yang dirasakan Lia Aminuddin adalah ketika mengakui bertemu dengan pemimpin spiritualnya yang pada akhirnya diklaim mengaku sebagai Jibril. Dari kejadian itu, Lia kemudian mengakui menerima pesan dan bimbingan langsung dari Jibril. Pengakuan Lia Eden ini semakin memberikan keyakinan kepada dirinya bahwa memang ada kekuatan yang membimbingnya untuk keluar dari dogma agama dan melewati segala ujian tersebut dengan penuh kesabaran dan ketabahan.

Perjalanan spiritual Lia Eden ketika mengaku menerima bimbingan dari Malaikat Jibril, perlahan tapi pasti ia mulai memperkuat proses meditasi yang dianggapnya sebagai langkah primordial dalam mendirikan kerajaan Tuhan (Kingdom of God). Langkah tersebut dianggap sebagai cara untuk memantapkan keyakinannya meskipun nanti akan memperoleh banyak tantangan dari 
masyarakat. Salah satu pengakuannya yang kontroversial adalah Malaikat Jibril dianggap telah menyucikan dan membimbingannya untuk menjalankan laku spiritual melalui latihan-latihan yang menguras energi dan mental. Pengakuan yang tidak kalah kontroversialnya adalah ketika mengaku bahwa ia dinyatakan Tuhan sebagai representasi dari surgawi-Nya di dunia. Sebuah pengakuan yang sangat mengejutkan karena melampuai akal sehat dan ajaran agama Islam yang menolak pernyataan-pernyataan seperti itu. ${ }^{6}$

Lia Eden yang mengakui menerima wahyu dari Malaikat Jibril, sesungguhnya ingin mengatakan bahwa dirinya adalah adalah manifestasi Tuhan yang bertugas menjadi jurus selamat atau ratu adil bagi permasalahan yang menimpa manusia modern. Sosok yang mengaku Jibril inilah yang sebenarnya menjadi "episentrum" yang mengendalikan jamaah Lia Eden sehingga ketika Jibril memberikan instruksi yang aneh-aneh, seperti menyebarkan surat-surat yang berisi wahyu penghapusan semua agama, anggota komunitas Eden tidak bisa berbuat lain kecuali menaatinya tanpa perlawanan.

Dengan latar belakang inilah-di mana Jibril menjadi episentrum Jamaah Lia Eden-kita bisa memahami sepak terjang komunitas Eden yang terus merus melakukan pendekatan agar mendapatkan pengikut sebanyak mungkin. Lia Aminudin, seperti diceritakan dalam ceramah-ceramah, risalah-risalah, dan buku-bukunya yang dikirimkan kepada publik, dinyatakan telah dipilih Tuhan untuk memimpin sebuah era baru bahwa umat manusia akan diperintah langsung oleh Jibril melalui sebuah Kerajaan Tuhan (Kingdom of God).

Berbagai pengakuan Lia Eden tentang dirinya merupakan cikal bakal lahirnya sebuah gerakan agama baru yang mencoba menawarkan dirinya sebagai sang juru selamat di dunia. Dengan mengatakan bahwa dirinya sebagai sosok surgawi-Nya di dunia, berarti ia telah menancapkan pengaruhnya untuk menarik pengikut sebanyak mungkin demi mencapai cita-cita dalam mendirikan sebuah kerajaan surga yang membawa kedamaian dan keharmonisandunia. Citacita untuk mendirikan kerajaan surga sesungguhnya berakar dari fenomena yang terjadi di Indonesia yang dianggapnya harus dibenahi dengan mendatangkan juru selamat yang mampu menjawab segala persoalan dan mengatasi segala krisis yang menimpa manusia modern sekarang ini.

${ }^{6}$ Al Makin, Nabi Palsu, 25.

JURNAL THEOLOGIA — Volume 29, Nomor 1, Juni 2018 
Lia Eden sendiri dalam penjelasannya, yang ia tulis dalam bukunya ${ }^{7}$ mengakui bahwa ia sempat ragu apakah yang ia terima merupakan kekasyafan atau sesuatu yang ia terima dari Malaikat ataukah jin. Berbagai pengalaman spiritual dan ujian, telah mengantarkan Lia pada suatu titik keyakinan puncak bahwa yang ia terima merupakan bentuk kekasyafan yang datang dari Tuhan melalui Malaikat-Nya. Kekasyafan yang memuncak ini pada akhirnya sampai pada keyakinan bahwa Tuhan mendatangkan suatu ujian yang mengantarkannya pada suatu keadaan yang menuntutnya harus membebaskan diri dari segala simbol dan "kategori". Dalam keadaan semacam ini, dia sudah tidak peduli apakah yang ia yakini dan dapatkan selama itu sesat atau selamat. Dia pasrah dan berserah diri pada Tuhan. ${ }^{8}$

\section{Ajaran Esensial Komunitas Lia Eden}

Komunitas Lia Eden yang sering disebut sebagai aliran Salamullah merupakan sebuah gerakan agama baru yang menghimpun semua agama-agama, baik Kristen, Islam, Yahudi, Budha, Hindu, Konghucu, Tao, dan lain sebagainya. Komunitas ini didirikan oleh Lia Aminuddin, di Jakarta yang kemudian mengganti namanya dengan Lia Eden. Kendati komunitas yang dianggap sempalan ini tidak menunjukkan pengaruh yang cukup luas, namun keberadaannya sempat membuat publik terkejut dengan beberapa pengakuan yang kontroversial. Beberapa pengakuan tersebut memang tidak lazim dalam mainstream agamaagama, bahkan berani melawan hirarki dan struktur agama formal yang sudah diakui. Tidak heran bila komunitas Lia Eden termasuk katagori agama sempalan yang dilarang untuk menyebarluaskan ajarannya ke ruang publik.

Pengakuan Lia Eden yang kontroversial tidak hanya melawan arus utama institusi agama formal yang menjadi way of life bagi keberlangsungan hidup manusia, namun juga berani melawan dengan tegas untuk menghapusnya dari muka bumi. Lia mengaku sebagai Imam Mahdi yang mempercayai reinkarnasi (kebangkitan kembali). Sebuah pengakuan yang sangat mengejutkan banyak pihak, terutama kalangan umat Islam yang menolak secara tegas akan sebuah pernyataan yang bertentangan dengan ajaran agama.

${ }^{7}$ Lia Aminuddin, Perkenankanlah Aku Menjelaskan Sebuah Takdir Uakarta: Yayasan Salamullah, 1998), 39.

${ }^{8}$ Mukhsin Jamil, Agama-agama Baru di Indonesia (Yogyakarta: Pustaka Pelajar, 2008), 105. 
Lalu bagaimana gambaran umum tentang ajaran Salamullah atau komunitas Lia Eden ini? Lembaga ini memang bercorak keislaman, namun dalam praktiknya berbeda jauh dengan karakteristik Islam normatif yang mengikuti tuntunan Nabi Muhammad. Ajaran Salamullah atau Lia Eden berupa menampilkan citra sebagai komunitas agama baru yang jauh dari kesan konflik dan kekerasan dengan menghadirkan formulasi baru yang lebih mencerahkan dalam bingkai spiritual. Dengan segala daya dan kekuatan, komunitas Lia Eden meyakinkan masyarakat bahwa masa depan agama sudah tidak lagi menjanjikan untuk memberikan ketenangan hidup, justru semakin membuat manusia terapung dalam dosa dan kenistaan duniawi. Di tengah carut-marutnya duniawi terutama karena semakin maraknya konflik dan kekerasan, komunitas Lia Eden menawarkan terapi baru yang lebih memukau dan memberikan ketenangan batin. Deepak Copra memahami bahwa komitmen spiritual dapat menjadi resolusi atas krisis ke arah zaman baru (New Age) yang penuh cinta, kasih sayang, damai, dan harmoni. ${ }^{9}$

Kehadiran komunitas Lia Eden dalam dinamika kehidupan agama di Indonesia, memang tidak bisa diterima begitu saja karena gerakan ini cenderung menyamakan semua agama. Ajaran-ajaran Lia Eden yang disebarkan melalui buku-buku dan ceramah-ceramahnya, kerapkali mengatakan, bahwa semua agama adalah jalan yang benar menuju Tuhan, yang berpegang pada prinsip panteisme (all is God and God is all). Kegemarannya terhadap paham reinkarnasi, mengingatkan kita kepada paham-paham yang dianut oleh New Age di Barat.10 Jadi walaupun belum ada data resmi, tetapi gejala agama dan spiritualitas gadogado, yang ditopang oleh sikap "tourist of religion" terus berkembang.

Ajaran komunitas Lia Eden memang bersebarangan dengan institusi agama formal, namun keberadaanya patut diapresiasi karena bisa membangkitkan motivasi pemeluk agama-agama untuk kembali pada nilai-nilai spiritualitas yang mengedepankan keinsyafan rohani sebagai obat penawarnya. Sejarah kemunculan agama-agama baru di dunia selalu memperbaiki kondisi-kondisi agama yang ada sebelumnya dengan fokus memberikan "penghargaan" terhadap manusia yang makin rasional, dewasa, dan mempercayai kedaulatan ilmu

\footnotetext{
${ }^{9}$ Deepak Copra, Quantum Healing: Exploring the Frontiers of Mind/Body Medicine (New York: Bantam Books, 1989), 234.

${ }^{10}$ Chandler, Understanding The New Age (New York: Pantheon Book, 1988), 20.
} 
pengetahuan. Kehadiran komunitas Lia Eden memang lebih mempercayai ramalan-ramalan masa depan, menghidupkan kultus, dan puncaknya meyakini kedatangan Sang Mesiah yang mempunyai otoritas tunggal dalam menyelamatkan bumi dan mengatur kehidupan manusia. Dan Sang Mesiah itu, menurut Komunitas Eden, kini sudah hadir dalam sosok Lia Aminudin sebagai pemimpin utamanya.

Kendati menunjukkan sebuah kelompok agama baru yang cenderung bercorak Islam, namun gerakan ini merengsek masuk pada agama-agama formal lainnya. Kelompok Salamullah atau Lia Eden menggambarkan eksistensinya sebagai Islam yang keras dan cocok terutama untuk masuk secara meyakinkan dalam kehidupan modern, terutama bagi kelas menengah dan orangorang Muslim yang kaya, yang menabrak tapal batas pluralisme yang dibatasi. Salamullah melalui media spiritual, mistik, magic Jawa, motif-motif messianistik dan kepercayaan reinkarnasinya telah secara berani "menantang" bentuk bentuk agama konvensional modern. Bagi gerakan agama baru seperti Lia Eden, mereka cenderung alergi terhadap agama formal karena dinilai cenderung eksklusif, dogmatis, dan sektarian.

Bagi komunitas Lia Eden, jalan lurus itu tidak harus dengan mengikuti agama formal yang cenderung eksklusif dan memaksa orang untuk masuk ke dalamnya. Bahkan agama formal seringkali menjadi biang keladi dari suburnya arus kekerasan yang mengancam keselamatan hidup dan lingkungan secara umum. Lia Eden hadir dengan kemasan yang lebih mencerahkan dan memberikan daya tarik yang lebih memikat daripada sekadar berkutat pada formalisme agama yang terkesan kaku, dogmatis, dan sektarian. Menurut pemikir India terkemuka, Baghavan Das, gerakan atau komunitas keagamaan yang menekankan pada spiritualitas adalah sebagai cermin New Age yang mengusung ide kesatuan esensial agama. ${ }^{11}$

Gerakan Lia Eden tidak mengajarkan teori bagaimana seorang murid harus suluk, fana, dan ma'rifat. Semua orang yang mengikuti jalan Salamullah langsung berjuang untuk hidup dalam kesucian dan perjalanan spiritual yang menakjubkan. Hal ini dimulai dengan pertobatan (pengakuan dosa mirip ajaran Kristen), berjanji untuk hidup suci dan tunduk patuh kepada apa yang diajarkan oleh 124.

11Bhagavan Das, The Essensial Unity of All Religions (Illionis: The Theosophical Press, 1966), 
Jibril. Setelah itu dicukur rambut ubun-ubun dan diolesi spiritus kemudian dibakar. Selanjutnya penganut baru ini hidup dalam komunitas spiritual yang kini mereka menyebut kelompoknya sebagai "kaum Eden". Jibril dalam pandangan kaum Salamullah adalah guru atau syaikh mereka yang mengajarkan kebenaran dan keadilan serta meluruskan kembali ajaran-ajaran agama yang mentradisi dan menjadi kultus. Keyakinan terhadap Jibril dan ajaranajarannya merupakan inti dari paham Salamullah. ${ }^{12}$

Kaum Salamullah meyakini bahwa Jibril kembali turun ke bumi untuk mengajar dan membimbing manusia menuju keselamatan. Jibril datang untuk meluruskan semua ajaran agama dari penyimpangan-penyimpangan yang dilakukan oleh pemuka-pemuka agama baik secara sengaja maupun tidak seperti kultus kepada pemimpin agama, keyakinan terhadap benda-benda keramat, dan berbagai macam kemusyrikan. Sebaliknya, Tuhan adalah segalagalanya. Perdamaian adalah misi atau tugas suci, karenanya semua agama harus bekerja sama saling bahu-membahu untuk Tuhan. Semua nabi dan rasul mengajarkan ajaran yang sama, karenanya semua kitab suci diajarkannya kembali secara sungguh-sungguh dan akhirnya terlihatlah benang merah kehendak Tuhan dan kebenaran itu berkesinambungan. ${ }^{13}$

Geliat pemikiran komunitas Lia Eden yang mencoba mengemban misi suci demi meraih titah Ilahi, tetap saja tidak bisa diterima oleh kaum beragama. Ajarannya secara eksplisit memang bertentangan dengan mainstream agama formal, bahkan dengan lantang menyuarakan ke pengikutnya untuk menghapus agama-agama formal yang dianggap tidak memiliki masa depan. Di Barat, khususnya Amerika Utara, situasi ini agak serupa justru diiringi dengan semakin meningkatnya ketidakpercayaan pada institusi agama formal (a growing distrust of organized religion). Hal ini sesuai dengan apa yang dinyatakan oleh futurolog John Naisbitt dan Patricia Aburdene dalam bukunya "Megatrend 2000", Spirituality Yes, Organized Religion No!" 14

${ }^{12}$ Ahmad Syafi'i Mufid, "Kuasa Jibril: Dari Sufisme Perenial, Salamullah Hingga Spritualisme Eden," dalam Urban Sufism, ed. Martin van Bruinessen dan Julia D. Dowell Oakarta: Rajawali Press, 2008), 413.

13Mufid, "Kuasa Jibril," 413.

${ }^{14}$ Naisbitt dan Aburdene meramalkan bahwa salah satu kecendrungan baru menjelang abad 21 adalah "The Religious Survival of the New Millennium", banyak pihak, yang menyebutnya dengan antusias, karena seakan-akan mengukuhkan harapan kembalinya "kebangkitan agama" setelah 
Lalu bagaimana dengan agama yang memiliki masa depan? Ramalan Naisbitt dan Aburdene tentang masa depan agama sesungguhnya tidak dibarengi dengan analisa yang kuat, karena nyatanya agama-agama formal yang diramalkan sebagai tidak memiliki masa depan justru semakin menunjukkan kekuatannya. Agama Yahudi semakin kuat dipeluk oleh orang Israel. Agama Kristen tetap banyak dipeluk oleh orang-orang Barat, meskipun frekuensi kehadiran ke gereja menurun drastis. Islam juga semakin menunjukkan revivalitasnya-walaupun baru sebatas ukuran kuantitas-karena semakin bertambahnya bangsa-bangsa lain yang tadinya non-Muslim beralih menjadi pemeluk agama Islam. 15

Barangkali agama yang disinyalir Naisbitt dan Aburdene sebagai tidak memiliki masa depan adalah agama yang dikatagorikan sebagai agama kultus, yaitu bentuk gerakan keagamaan dengan sistem pengorganisasian yang ketat dan pemujaan terhadap guru spiritual secara berlebihan serta dengan disiplin yang cukup rumit, eksklusif, absolutistik, dan dengan sendirinya bersifat isolatif serta kurang toleran terhadap kelompok lain. Meminjam pendapatnya Arnold bahwa agama yang cocok untuk dunia modern adalah keberagaman kaum sufi atau esoterisme Tao, karena keduanya dinilai sangat humanis, inklusif, dan tidak bertentangan dengan prinsip-prinsip antropis dan hukum Islam. ${ }^{16}$

Agama masa depan yang ditawarkan barangkali adalah agama yang memperjuangkan prinsip-prinsip antropik-spiritualisme. Secara epistemologis, agama masa depan menolak absolustisme, melainkan memilih apa yang oleh Swidler ${ }^{17}$ disebut deasolutizing truth atau yang oleh Sayyed Hossein Nasr diistilahkan sebagai relatively absolute. Begitu pula dengan kemunculan gerakan

ditelan modernitas yang membawa sekularisasi. Namun antusiasme itu, seketika berubah, ketika di bagian lain, mereka mengumandangkan realitas lain (the other reality) tentang "Spirituality, yes; Organized Religion, no." Apa yang diintroduksi Naisbitt dan Aburdene ini, sesungguhnya mencerminkan kegelisahan lama ketika dalam masyarakat tertentu menunjukkan kecenderungan bahwa agama terlalu sering diinstitusionalisasikan dalam berbagai lembaga formal, atau agama dipolitisasi dalam berbagai bentuk kepentingan politik praktis. Lihat: John Naisbitt and Particia Aburdene, Megatrends 2000: Ten New Directions for the 1990's (New York: Avon Books, 1991), 295.

${ }^{15}$ Nurcholish Madjid, "Beberapa Renungan tentang Kehidupan Keagamaan di Indonesia Untuk Generasi Mendatang” (Naskah Ceramah Budaya, Taman Ismail Marzuki Jakarta, 1992).

${ }^{16}$ Arnold Arnold, The Corrupted Sience: Challenging the Myths of Modern Science (London: Paladin, 1992), 234.

17Leonard Swidler, After the Absolute, The Dialogical Future of Religious Reflection (Minneapolis: Fortress Press, 1990), 7. 
keagamaan atau spiritualitas baru yang mengusung pencerahan sebagai basis transformasi, semisal komunitas Lia Eden.

Dalam kasus Lia Eden, ada semacam penolakan terhadap agama formal yang memiliki gejala umum yang hampir sama, yaitu eksklusif dan dogmatissambil menengok ke arah spiritualitas baru lintas agama. Sebagaimana diketahui bahwa komunitas Lia Eden adalah komunitas keagamaan atau lebih tepatnya komunitas spiritual yang senantiasa hidup dalam kesucian dan mendekatkan diri kepada Allah, zuhud secara total. Coraknya adalah mesianistik yang meyakini tentang dibangkitkannya kembali ruh Nabi Isa dan Imam Mahdi untuk menyatukan kembali umat Kristen dan Islam. Bagi penulis, komunitas Lia Eden merupakan sebuah keyakinan dan kepercayaan yang mencerminkan spiritualitas baru dengan konsep reinkarnasi sebagai salah satu ajarannya.

Tidak heran bila komunitas Lia Eden atau kelompok Salamullah adalah agama baru yang bersendikan pada perenialisme, sebuah keyakinan bahwa hakikatnya seluruh agama memiliki sumber yang sama, yaitu Tuhan Yang Maha Esa. Dalam pandangan komunitas Lia Eden, agama-agama formal hanyalah intitusi yang dapat mengkungkung pemeluknya dan mengantarkan pada kebekuan dogmatis-normatif. Ketika mendapatkan pengajaran dari Jibril, Lia Eden sebagai pemimpin gerakan Salamullah mengedepankan spiritualitas baru untuk mendapatkan pencerahan dari sang Ilahi. Tanpa harus mengakui agama dan menformalkan sebuah keyakinan dalam struktur yang terorganisasi, setiap bisa saja mendapatkan pencerahan secara spiritual melalui pengalaman langsung yang diperoleh melalui ilham atau wahyu yang diklaim sebagai manifestasi dari perintah Tuhan.

Pengalaman spiritual yang diperoleh Lia Eden sebagai pemimpin gerakan Salamullah dapat dijadikan sebagai gambaran untuk mendalami ajaran-ajaran yang memberikan daya tarik bagi petualangan spiritualitas lintas agama. Ajaranajaran spiritual yang dibawa komunitas Lia Eden memang terkesan bertentangan dengan mainstream agama formal. Pengajaran Jibril selanjutnya adalah spiritulitasme tanpa agama, yang mendasarkan religiositas kaum Eden pada tauhid (absolute monotheism), kesucian, ketundukan kepada Tuhan yang terwujud dalam buah moralitas keseharian.

Lalu kenapa komunitas Lia Eden dianggap sebagai splinter group? Apakah ajarannya memang bertentangan dengan arus utama dalam mainstream agama konvensional? Penjelajahan Salamullah menjadi kontroversial karena me- 
masuki masalah-masalah tauhid, regulasi ruh, keabadian, dan berbagai idiom yang kurang akrab di telinga kebanyakan orang. Salamullah juga memiliki dunia simbol dan ritus yang sangat berbeda, dan bahkan berseberangan dengan ritus dan simbol yang sudah mengakar kuat dalam masyarakat. Dengan melihat hal tersebut, kelompok ini bisa dikatakan sebagai aliran baru dengan struktur kelembagaan dan sistem kepercayaaan yang baru pula.

Pada kasus Lia Eden yang telah divonis sebagai gerakan terlarang, ada beberapa pengakuan yang melandasi komunitas ini disebut splinter group. Pertama, menganggap dirinya sebagai Mesias. Selain menganggap dirinya sebagai orang yang menyebarkan wahyu Tuhan dengan perantaraan Jibril, dia juga menganggap dirinya memiliki kemampuan untuk meramalkan kiamat. Selain itu, ia mengaku sebagai sang juru selamat yang akan menentukan terhadap semua kehidupan umat manusia. Ajaran-ajaran yang kontroversial ini ternyata banyak diikuti oleh berbagai macam profesi, terutama dari golongan menengah ke atas yang memiliki tingkatan pendidikan yang cukup tinggi. ${ }^{18}$

Gerakan Lia Eden memang sempat menimbulkan kehebohaan di kalangan umat Islam, karena menurutnya ritual agama yang bersifat formalistik tidaklah penting dibandingkan dengan spiritualitas itu sendiri. ${ }^{19}$ Pada tahun 2000, ajaran Salamullah ini diresmikan oleh pengikut-pengikutnya sebagai nama kelompok. Anehnya, kelompok Salamullah mengakui bahwa Nabi Muhammad adalah sebagai Nabi yang terakhir, tetapi juga mempercayai bahwa pembawa kepercayaan yang lain seperti Buddha Gautama, Yesus Kristus, dan Kwan Im, juga mengandung kebenaran yang berusaha mencapai pengalaman spiritual yang lebih substansial. ${ }^{20}$

\footnotetext{
18Jamil, Agama-agama Baru ..., 26.
}

${ }^{19}$ Sebagian besar mitos mungkin saja didasarkan atas peristiwa historis, tetapi tidak semua peristiwa historis memperoleh watak mistis. Cerita mitos yang kuat pengaruhnya dan masih sering dipercaya oleh orang jawa adalah kepercayaan kepada Nyi Roro Kidul, dengan gambaran seorang ratu peri yang sakti dan cantik, yang menguasai dunia mahluk halus Samudra Hindia atau Segara Kidul. Daniel J. Adam, Teologi Lintas Budaya: Refleksi Barat di Asia Oakarta: BPK Gunung Mulia, 1991), 99.

${ }^{20}$ Pengalaman spiritual adalah dengan berusaha mencapai ekstase, atau pengalaman keagamaan yang melampaui segenap kesadaran indrawi dan logika. Perasaan bahagia luar biasa yang tidak dapat diterangkan dengan akal juga merupakan sesuatu yang sering menyertai pengalamanpengalaman mistik. Ajaran penting lainnya adalah konsep mengenai apa yang disebut dengan "Yang Tunggal." la tidak dapat dipahami oleh orang biasa dan merupakan dasar bagi segala sesuatu. Meskipun tidak dapat dipahami, namun ia hadir dalam diri kita, dan dengan menyadarinya secara internal kita dapat mencapai kemanunggalan dengan segala sesuatu di sekeliling kita. Tujuan 
Kecenderung lain tentang pemikiran dan ajaran komunitas Lia Eden yang kontroversial dan bertentangan dengan mainstream agama formal adalah fatwa Allah yang menyatakan bahwa babi tidak haram lagi. Bagi komunitas ini, label halal itu kini tidak penting lagi. Di zaman ketika ternak riskan dikonsumsi karena penyakit flu burung, sapi gila, anthrax membahayakan binatang ternak, Tuhan menghalalkan daging babi. Dan pula, demi menyamakan persepsi hidangan di antara semua umat yang diharapkan menemukan perdamaian, maka tidak ada lagi perbedaan makanan di antara semua umat. Perdamaian di masa sekarang ini amat penting. Segala perbedaan diupayakan untuk dihapuskan. Tuhan mengangkat pengharaman atas daging babi. Maka, ruh-ruh jahat tidak lagi ditiupkan kepada babi.

Kepercayaan komunitas Lia Eden tentang kehalalan babi memang tidak bisa diterima oleh akal sehat dan ajaran Islam yang jelas-jelas mengharamkan babi sebagai makanan. Bagai komunitas ini, pada awalnya babi memang makanan yang terlarang karena dahulu menjadi binatang yang ruhnya merupakan jenis ruh jahat. Namun di zaman yang serba kesulitan ini, dunia penuh dengan wabah penyakit dan mengancam keselamatan umat manusia, maka daging babi yang disukai dapat dijadikan sebagai salah satu solusi untuk memperkuat perdamaian. Komunitas Lia Eden tidak ingin ada pemisahan mengenai hidangan Muslim dan non-Muslim karena tidak semua Muslim sendiri merasa jijik terhadap daging babi. Pengharaman babi hanya akan membuat umat Islam terpecah-pecah dan mudah tersulut api permusuhan, sehingga perdamaian di antara umat beragama yang berbeda-beda itu sangat penting. Maka, dihalalkanlah babi dalam aliran ini.

Keunikan lain dari aliran ini adalah keyakinan terhadap surga dunia yang dianggapnya sebagai kenyataan yang harus tampak dalam kehidupan manusia. Buktinya, para Nabi dibangkitkan untuk menyatakan surga-Nya. Kerajaan Tuhan (Kongdom of God) diresmikan agar umat manusia mampu melihat eksistensi Tuhan dengan lebih dekat dan nyata tanpa sekat sekalipun. Bagi komunitas Lia Eden, di zaman ketika doa jarang dikabulkan ini, adalah penting menyatakan Surga dan kehadiran Tuhan yang nyata. Mereka juga mengatakan bahwa surga bukan khayalan dan tidak teraih serta hanya terjadi di akhirat.

tertinggi umat manusia adalah menyatu dengan "Yang Tunggal" sehingga mencapai titik kulminasi spiritual yang tinggi. Lihat: Sachiko Murata, Gemerlap Cahaya Sufi Dari Cina (Yogyakarta: Pustaka Sufi, 2003), 3. 
Bukan pula janji Tuhan yang tidak terlihat keadaannya bila sudah ditepati. Ada Surga di alam akhirat, tapi itu berarti dunia kemalaikatan. Manusia tidak menjadi malaikat bila ruhnya tidak cukup suci. Kesucian yang dipersyaratkan adalah kesucian tanpa noda.

Dalam komunitas Lia Eden ini ada satu ritual yang harus dijalani untuk menyucikan umatnya dari dosa-dosa yang diperbuatnya. Ritual itu dilaksanakan dengan cara penggundulan seluruh rambut dan pembakaran sekujur tubuh. Ajaran tersebut menurut Lia, merupakan perintah langsung dari Allah yang disampaikan oleh Malaikat Jibril kepadanya. Menggunduli rambut dan membakar tubuh merupakan hisab (perhitungan Allah) untuk membersihkan diri dari segala dosa. Setelah melaksanakan ritual tersebut, maka mereka seperti bayi yang baru lahir, bersih dan suci dari dosa.

\section{Visi Transformatif Komunitas Lia Eden: Embrio Gerakan New Age di Indonesia}

Barangkali komunitas ini hampir mirip dengan aliran deisme yang juga berpandangan bahwa agama-agama formal (organized religions), semisal Yahudi, Kristen, dan Islam, sudah tidak memiliki masa depan.21 Dalam lintasan sejarah, komunitas Lia Eden tampil sebagai bagian dari gerakan keagamaan dan spiritual yang cukup fenomenal-tentu selain fenomena kultus, sekte, pemikiran baru (new thought), gerakan "agama baru (new religious movement), gerakan "potensi manusia" (human potential movement), dan gerakan "kesehatan holistik" (the holistic health movement), yang kesemuanya begitu fenomenal dalam skala global.

\footnotetext{
${ }^{21}$ Agama formal yang ada mereka anggap tidak bisa memenuhi kebutuhan batin mereka untuk mendapatkan ketenangan, kedamaian dan kebahagiaan. Mereka menganggap aturan agama yang ada hanya membelenggu mereka. Belum lagi masing masing agama yang mengklaim ajarannya paling benar, kemudian menyalahkan agama lain yang berujung dengan saling serang antara satu dengan yang lainnya. Sekelompok orang yang tidak puas dengan ajaran agama yang ada mulai mencari cara hidup baru dengan meramu ajaran yang ada dari semua agama. Mereka mencampur adukan ajaran spiritual dari Islam, Kristen, Budha, Hindu dan tradisi kuno, jadilah spiritualitas gado gado yang mereka harapkan bisa memenuhi kebutuhan rohani mereka. Cara hidup dengan meramu berbagai ajaran agama ini dikenal dengan istilah Gerakan Zaman Baru (GZB) atau dikenal didunia dengan sebutan New Age Movement, yang muncul sejaktahun 1960 di Amerika. Barangkali yang bertahan bagi mereka adalah pesan-pesannya yang universal, sementara ritus-ritus formal dan label-label yang membungkusnya akan semakin ditinggalkan orang. Lihat: Komaruddin Hidayat and Muhamad Wahyuni Nafis, Agama Masa Depan: Perspektif Filsafat Perennial Uakarta: Gramedia Pustaka Utama, 2003), 159.
} 
Membaca fenomena New Age sebagai ide zaman baru yang banyak mengusung nilai-nilai spiritualitas memang cukup menarik untuk diungkap ke permukaan. New Age Movement pada awalnya muncul di Amerika Serikat. Sejak tahun 1970-an dan 1980-an, gerakan ini marak luar biasa dan melahirkan benih baru yang secara populer diekspresikan dalam bentuk "gerakan kesadaran diri" (self-conscious movement). ${ }^{22}$ Sebuah gerakan yang ingin mengusung keinsyafan rohani dari kalangan kaum beragama yang terkesan mengabaikan hakikat kehidupan untuk lebih mencintai perdamaian dibandingkan dengan konflik.

Apa yang disebut dengan New Age, sesungguhnya merupakan bagian dari gerakan untuk membangkitkan semangat spiritualitas dalam dimensi agama sehingga setiap umat manusia menyadari akan eksistensi dirinya di dunia. Gerakan ini tidak muncul dalam suatu bentuk agama atau organisasi tertentu walaupun dalam aktivitasnya seringkali menerapkan kaidah organisasi politik, ekonomi dan sosial. Penampilannya juga termanifestasi dalam bentuk seperti latihan kesehatan, pernafasan dan meditasi. Gerakan ini mempraktikkan kepercayaan agama pantheisme seperti Hinduisme, Budhisme, Taoisme. ${ }^{23}$ Dengan kata lain, bahwa gerakan ini memunculkan sebuah pemahaman tentang pentingnya mengambil konsep meditasi sebagai bahan renungan dalam memaknai kehidupan yang penuh dengan tantangan ini.

Bila ditelusuri, ideologi inti dari Gerakan Zaman Baru (New Age Movement) adalah "pantheisme" yang tercermin dalam "God is all and all is god". Oleh karena itu, New Agers sangat menghayati betul arti pentingnya monisme (segala sesuatu yang ada, merupakan derivasi dari sumber tunggal, divine energy), pantheisme (all is God and God is all), sebuah kepercayaan bahwa alam semesta adalah cerminan dari Tuhan, karena ia menyatu dengan segala sesuatu yang diciptakannya. Para New Agers juga mempercayai akan reinkarnasi ${ }^{24}$ yang merepresentasikan bahwa manusia akan bangkit kembali setelah kematian sehingga bisa menikmati kehidupan lain. Hal ini juga terdapat dalam beberapa ajaran spiritualitas dalam agama Hindu yang dikenal dengan konsep transmigration of the soul. ${ }^{25}$

22Sukidi, New Age: Wisata Spiritual Lintas Agama (Jakarta: Gramedia Pustaka Utama, 2001), 3.

23James Legge, The Texts of Taoism (Singapore: Graham Brash, 1979), 1.

${ }^{24}$ Chandler, Understanding The New Age, 133.

${ }^{25}$ Spiritualitas pada hakikatnya adalah pengalaman langsung dalam kesadaran seseorang. Spiritualitas dalam pandangan Mahatma Gandhi adalah hidup degan kesadaran bahwa Tuhan senantiasa di dekat kita (spirituality is livinng in the present of God always). Lihat: Gedong Bagoes Oka, 
Gerakan New Age dalam lintasan sejarah, awalnya memang terdiri dari kelompok-kelompok kecil (small groups) yang akrab disebut dengan "light groups",seperti theosophical, findhorn community dan chanelling groups. Gerakan "light groups" dipelopori oleh seorang pendiri gerakan teosofi, Helena P. Blavatsky, yang mendiskusikan untuk meramalkan kadatangan sang juru selamat di dunia. Gerakan ini bisa dipahami mirip dengan komunitas Lia Eden yang juga memprediksikan kedatangan suatu world savior, sang juru selamat dunia. Kehadiran sang juru selamat diproyeksikan akan menyelamatkan manusia dan alam semesta ini dari kehancuran total, namun masih sulit ditebak dan menimbulkan teka teki. Dalam kalangan komunitas Lia Eden, terdapat Imam Mahdi ataupun Isa al-Masih yang mungkin menjadi juru selamat bagi kehidupan manusia.

Sebagai diskursus intelektual, prediksi world savior yang digaungkan "light groups", sungguh menggiurkan, khususnya buat simpatisan komunitas Lia Eden yang merupakan embrio gerakan New Age. Menariknya, "light groups" tidak sekadar menampilkan prediksi, namun juga jaringan institusi sambil menawarkan "cahaya spiritual" (the spiritual light). Melalui institusi yang diberi nama "jaringan universal" (universal link), "light groups" tampak begitu artikulatif, visioner, dan transformatif memberikan pencerahan (enlightenment).

Ekspansi spiritual yang digulirkan "light groups" tampaknya sejalan dengan apa yang disuarakan komunitas Lia Eden untuk mencapai pengalaman spiritual tanpa harus terjebak dengan formalisme agama. Dalam aktifitas komunitas Lia Eden ternyata juga terdapat kepercayaan terhadap mistisisme yang merupakan bagian dari pengalaman religius yang lebih mendalam dengan berusaha untuk mencapai titik kulminasi dengan sang ilahi. Tidak heran bila bagi para sufi yang memperoleh pengalaman mistis merupakan sebuah indikasi pernyataan spiritual tentang ketiadaan (fana). ${ }^{26}$ Sebuah kesadaran spiritual dapat menghilangkan sikap agresivitas manusia yang cenderung eksploitatif dan diskriminatif.

Berkenaan dengan makin gencarnya jaringan "light groups" yang masuk pada semua dimensi spiritual sebuah gerakan keagamaan, termasuk komunitas Lia Eden, seorang teosofi, intelektual, dan spiritualis, David Spangler, berupaya

"Spiritualitas Baru dalam Agama Hindu," dalam Spiritualitas Baru Agama dan Aspirasi Rakyat, ed. Elga Sarapung, Alfred B. Jogo Ena, dan Noegroho Agoeng (Yogyakarta: Institut DIAN/Interfide, 2004), 29.

${ }^{26}$ Carl W. Ernst, Ekspresi Ekstase dalam Sufisme (Yogyakarta: Putra Langit, 2003), 288. 
membangun sebuah basis teoritis yang bisa memperkuat gerakan New Age secara lebih luas. Perhatian dan kontribusi Spangler terhadap ide besar dalam gerakan New Age yang menjadi cikal bakal lahirnya sebuah gerakan keagamaan tentu saja semakin memperkuat kekuatan jaringan mereka untuk mencetuskan spiritualitas baru yang lebih mencerahkan. Terbukti karya besar berjudul Revalation The Birth of a New Age, ${ }^{27}$ meluncur ke arena publik. Ia juga berhasil menghasilkan karya yang sangat fenomenal yang berjudul Emerrgence, The Rebirth of the Sacred. ${ }^{28}$

Lewat karyanya yang cukup monumental, ia lantas mengidentifikasi level gerakan New Age dengan artikulatif dan memberikan daya tarik tentang kekuatan batin (psychic power) bagi nilai-nilai humanisme. Model yang cukup menaruh perhatian adalah paradigma perubahan yang dikedepankan oleh Marilyn Ferguson dalam "Konspirasi Aquarian".29 Level New Age selanjutnya adalah secara paradigmatik ingin mendefinisikan ulang makna "kesucian" (redefining of the sacred) dan sekaligus mensakralisasikan ulang bumi, manusia, dan kehidupan sehari-hari. Level New Age inilah yang barangkali menjadi titik awal kebangkitan spiritualitas New Age (Ne Age Spirituality).

Terlepas dari perkembangan New Age yang meluas ke berbagai belahan dunia, komunitas Lia Eden tidak luput dari pengaruh ide dan gagasan yang digulirkan para New Ager yang mencoba menghayati akan sebuah konsep yang dikenal dengan monoisme (sebuah faham bahwa segala sesuatu yang ada di dunia ini adalah berasal dari yang satu atau tunggal). Pada saat yang sama, para New Ager juga percaya bahwa Tuhan adalah cerminan dari alam semesta, begitu pun sebaliknya.Gerakan Salamullah atau komunitas Lia Eden sesungguhnya bukan bermaksud mendirikan agama baru sebagaimana yang diasumsikan banyak orang. Justru yang menjadi visi transformatif komunitas Lia Edensebagaimana juga New Age adalah apa yang dirumuskan oleh J. Gordon Melton ${ }^{30}$ sebagai salah satu bentuk tranformasi mistik-radikal pada level individu.

\footnotetext{
${ }^{27}$ David Spangler, Revelation: The Birth of a New Age (San Fransisco: Rainbow Bridge, 1976), 131.

${ }^{28}$ David Spangler, Emergence: The Rebirth of the Sacred (New York: Dell, 1984), 45.

${ }^{29}$ Marilyn Ferguson, Aquarian Conspiracy: Personal and Social Transformation in Our Time (Los Angeles: Jeremy P. Tarcher, 1987), 134.

30J. Gordon Melton, Encylopedic Handbook of Cults in Amerika (New York: Garland Publishing, 1986), 113.
} 
Visi transformatif komunitas Lia Eden bukan berambisi ingin mendirikan institusi baru yang bersifat keagamaan dengan organisasi yang ketat dan bersifat doktrinal, melainkan berupaya untuk mentransmisikan kekuatan spiritual pada level individu hingga menjadi cerminan dari gerakan mistik. Bahkan dalam literatur New Age mutakhir, New Religions and the Theological Imagination in Amerika, Mary Farrell Bednarowski juga sepakat dengan identifikasi kelompok New Age yang ditawarkan guru spiritual, David Spangler melalui rumusan populernya, yaitu "komunitas-komunitas spiritual yang sengaja mendukung kebangkitan kebudayaan baru dengan didasarkan pada transformasi manusia".

Bila ditarik dalam kehidupan nyata dewasa ini, maka pengalaman mistik pada level individu dapat dikatagorikan sebagai sebuah petualangan spiritual yang patut diapreasi, karena menunjukkan adanya proses transformasi kualitatif pada diri manusia itu sendiri. Sebagai bagian dari petualangan spiritual, pengalaman mistik memang bertujuan untuk menjalin harmoni dengan "divine energy" yang banyak dilakukan oleh para mistikus agama-agama.

Visi transformatif komunitas Lia Eden sebagai embrio dari gerakan New Age adalah berpijak dari transformasi personal ke arah transformasi sosial. Pada level individu, visi transformatif Lia Eden berlangsung secara personal dan banyak mencerminkan pengalaman mistik-spiritual. Sebagai gerakan keagamaan dan spiritualitas baru yang menjelajahi dimensi esoteris, metafisik, dan spiritualisme (the esoteric, metaphysical, spiritualism), pengalaman mistik komunitas Lia Eden-yang secara praktis adalah a free-flowing spiritual movement, terartikulasikan dalam berbagai manuskrip metafisika-spiritualitas. Sebagai universal way, dimensi esoteris Tao seringkali dipakai oleh kalangan spiritualis, mistikus, dan penganut setiap gerakan komunitas Lia Eden sebagai "filsafat kehidupan" (philosophy of life) yang membawa kearifan dan kebijaksanaan hidup. Kita bisa menyebut bahwa dimensi esoteris yang dipakai komunitas Lia Eden adalah ancient wisdom, suatu kearifan batin yang sedang diburu manusia untuk mengobati krisis identitas dan cara pandang hidup yang menjadi sindrom bagi manusia modern sekarang ini.

Pada level ini, gerakan yang digulirkan komunitas Lia Eden boleh dikatakan sebagai salah satu kebangkitan spiritualitas yang mengedepankan pengalaman mistik sebagai jalan menuju kedamaian dan keharmonisan. Sejalan dengan konsep tersebut, ajaran Salamullah atau komunitas Lia Eden bisa dikatakan 
sebagai fenomena New Age yang paling ekspresif dan menjadi trend dalam kebangkitan spiritualitas. Merebaknya gerakan masif dari generasi New Age, termasuk kelompok Lia Eden yang selalu menyebut-nyebut dirinya sebagai "generasi bunga", ternyata memang tetap berkiblat pada mainstream spiritualitas, ${ }^{31}$ mulai menyelami manuskrip Celestine sampai mengalami apa yang menjadi tradisi spiritual komunitas Lia Eden sebagai spiritual gathering dengan berbagai variasi mistik-spiritualitasnya.

Sebagai bagian dari New Age masa kini, komunitas Lia Eden berupaya berjuang untuk menancapkan pengaruhnya dengan menjadikan meditasi spiritual sebagai instrumen penyatuan dan kesadaran diri. Kendati tidak memiliki pengikut yang banyak, komunitas Lia Eden tetap tampil dengan kemasan yang berbeda dibandingkan dengan gerakan spiritual lainnya yang banyak mengusung transformasi personal sebagai visi utamanya. Melalui visi transformatif yang bersifat personal, komunitas Lia Eden terus bergerak untuk menggulirkan transformasi sosial yang memberikan pencerahan bagi masyarakat yang dirundung problem akut terkait dengan krisis yang menimpa mereka di era modern sekarang ini.

Lalu kenapa paradigma komunitas Lia Eden dimulai dari transformasi personal menuju transformasi sosial? Hal ini sesuai dengan apa yang dirumuskan James Redfield bahwa "to change the world, we first had to change ours selves" (untuk mengubah dunia, kita harus mengubah diri kita terlebih dahulu). Jawaban tersebut kemudian diikuti pertanyaan selanjutnya, kenapa untuk mengubah dunia, kita harus mengubah diri kita terlebih dahulu? Menurut Deepak Copra "your attitude create the world" (sikap anda dapat menciptakan dunia). ${ }^{32}$ Dalam pemikiran komunitas Lia Eden, dunia ini harus direstorasi dari kondisi krisis ke arah zaman baru yang penuh cinta kasih dan kedamaian.

Di kalangan kelompok Lia Eden, kepekaan terhadap acutely-felt sense of crisis memang telah menjadi visi fundamental dan menjadi bagian dari titik sentral dari segala protes keras untuk menolak institusi agama formal yang

\footnotetext{
${ }^{31}$ Kecenderungan besar para mistik spiritual antara lain terbukti dengan begitu banyaknya literatur tentang mistik spiritual dewasa ini. Bahkan akhir-akhir ini sudah beredar antologi spiritual setebal 875 halaman yang menjadi trend di kalangan new age. Lihat: Lucinda Vardey, God in All Worlds: An Anthology of Contemporary Spiritual Writing (New York: Pantheon Book, 1995), 346.

${ }^{32}$ Copra, Quantum Healinng, 232.
} 
dianggap belum mampu mengatasi krisis kemanusiaan modern. Dewasa ini dunia memang sedang diguncang oleh krisis global. Fisikawan genius Fritjof Capra menyebutnya sebagai "stae of profound and world wide crisis".33 Krisis multidimensional ini, sudah mewarnai setiap aspek kehidupan, seperti kesehatan, lingkungan, hubungan sosial, dan sebagainya. Setidaknya, ada tiga krisis global yang bisa menghantam eksistensi manusia di era kontemporer ini.

Krisis global memang cukup menjadi perhatian komunitas Lia Eden dalam menggulirkan semangat untuk kembali pada spiritualitas baru. Kekhawatiran terhadap krisis yang menimpa manusia modern, dirasakan betul oleh pemikir New Age, Wounter J. Haneraaff yang menyebutnya dengan a point of extreme danger to humanity and the planet as a whole. ${ }^{34}$ Krisis semacam intelektual, moral, dan sekaligus spiritual, sesungguhnya tidak pernah terbayangkan dan tidak pernah terjadi dalam pentas sejarah kehidupan manusia. Kesadaran diri umat manusia memang menjadi penting untuk mengontrol dan mengendalika krisis multidimensional tersebut agar tidak semakin parah dan membahayakan nilai-nilai humanitas.

\section{E. Kesimpulan}

Komunitas Lia Eden yang dianggap bertentangan dengan mainstream agama formal memang menghadapi sebuah tantangan untuk bertahan di tengah kritikan dan kecaman yang terus-menerus bergelombang setiap saat. Bahkan bukan hanya berupa kecaman yang harus ditanggung, tapi juga menyangkut fatwa sesat dan menyesatkan serta pembubaran secara paksa melalui berbagai cara yang dilakukan oleh kelompok agama mainstream. Sebagai bagian dari splinter group, komunitas Lia Eden menyadari betul bahwa eksistensinya mulai dipertanyakan dan digugat oleh kelompok agama formal yang secara tegas menolak penyebaran ajaran secara luas ke ruang publik.

Kehadiran Lia Eden sesungguhnya bukan bermaksud mendirikan institusi baru, seperti agama formal pada umumnya. Esensi dari komunitas ini adalah spiritualisme tanpa agama. Banyak kalangan yang mengasumsikan bahwa kehadiran komunitas Lia Eden sebagai fenomena baru dalam mendirikan sebuah agama yang terorganisasi dengan rapi. Dalam komunitas ini, agama

${ }^{33}$ Capra, The Turning Point, 123.

${ }^{34}$ Hanegraaff, New Age Religion, 344. 
bukanlah suatu solusi untuk memecahkan segala krisis yang menimpa manusia modern sekarang ini, bahkan dianggap menjadi biang keladi dari semakin maraknya tindakan kekerasan dan konflik yang menimpa semua umat manusia. Sikap acuh tidak acuh, bahkan sikap alergi terhadap institusi agama formal merupakan kritik pedas komunitas Lia Eden yang sama sekali tidak percaya pada masa depan agama.[]

\section{DAFTAR PUSTAKA}

Adam, Daniel J. Teologi Lintas Budaya: Refleksi Barat di Asia. Jakarta: BPK Gunung Mulia, 1991.

Aminuddin, Lia. Perkenankanlah Aku Menjelaskan Sebuah Takdir. Jakarta: Yayasan Salamullah, 1998.

Arnold, Arnold. The Corrupted Sience: Challenging the Myths of Modern Science. London: Paladin, 1992.

Capra, Fritjof. The Turning Point, Science, Society, and the Rising Culture. New York: Bantam Book, 1987.

Chandler. Understanding The New Age. New York: Pantheon Book, 1988.

Copra, Deepak. Quantum Healing: Exploring the Frontiers of Mind/Body Medicine. New York: Bantam Books, 1989.

Das, Bhagavan. The Essensial Unity of All Religions. Illionis: The Theosophical Press, 1966.

Ernst, Carl W. Ekspresi Ekstase dalam Sufisme. Yogyakarta: Putra Langit, 2003.

Ferguson, Marilyn. Aquarian Conspiracy: Personal and Social Transformation in Our Time. Los Angeles: Jeremy P. Tarcher, 1987.

Hanegraaff, Wouter J. New Age Religion \& Western Culture, Esotericism in the Mirror of Seculer Thought. New York: Bantam Book, 1996.

Hidayat, Komaruddin, and Muhamad Wahyuni Nafis. Agama Masa Depan: Perspektif Filsafat Perennial. Jakarta: Gramedia Pustaka Utama, 2003.

Jamil, Mukhsin. Agama-agama Baru di Indonesia. Yogyakarta: Pustaka Pelajar, 2008. 
Legge, James. The Texts of Taoism. Singapore: Graham Brash, 1979.

Madjid, Nurcholish. "Beberapa Renungan tentang Kehidupan Keagamaan di Indonesia untuk Generasi Mendatang." Jakarta: Taman Ismail Marzuki, 1992.

Makin, Al. Challenging Islamic Ortodhoxy: Accounts of Lia Eden and Other Prophets in Indonesia. Switzerland: Springer International Publishing, 2016.

_—_. Nabi Palsu: Membuka Kembali Pintu Kenabian. Yogyakarta: Ar-Ruzz Media, 2003.

Melton, J. Gordon. Encylopedic Handbook of Cults in Amerika. New York: Garland Publishing, 1986.

Mufid, Ahmad Syafi'i. "Kuasa Jibril: Dari Sufisme Perenial, Salamullah Hingga Spritualisme Eden." dalam Urban Sufism, ed. Martin van Bruinessen dan Julia D. Dowell. Jakarta: Rajawali Press, 2008.

Murata, Sachiko. Gemerlap Cahaya Sufi Dari Cina. Yogyakarta: Pustaka Sufi, 2003.

Naisbitt, John, and Particia Aburdene. Megatrends 2000: Ten New Directions for the 1990's. New York: Avon Books, 1991.

Oka, Gedong Bagoes. "Spiritualitas Baru dalam Agama Hindu." dalam Spiritualitas Baru Agama dan Aspirasi Rakyat, ed. Elga Sarapung, Alfred B. Jogo Ena, dan Noegroho Agoeng. Yogyakarta: Institut DIAN/Interfide, 2004.

Spangler, David. Emergence: The Rebirth of the Sacred. New York: Dell, 1984.

——- Revelation: The Birth of a New Age. San Fransisco: Rainbow Bridge, 1976.

Sukidi. New Age: Wisata Spiritual Lintas Agama. Jakarta: Gramedia Pustaka Utama, 2001.

Swidler, Leonard. After the Absolute, The Dialogical Future of Religious Reflection. Minneapolis: Fortress Press, 1990.

Vardey, Lucinda. God in All Worlds: An Anthology of Contemporary Spiritual Writing. New York: Pantheon Book, 1995.

Yogaswara, A., dan Maulana Ahmad Jalidu. Aliran Sesat dan Nabi-nabi Palsu: Riwayat Aliran Sesat dan Para Nabi Palsu di Indonesia. Yogyakarta: Narasi, 2008. 